\title{
'Our Breadcrumb Trail through the Woods': Reflections on the Use of a Secret Facebook Group as a Strategy for Surviving and Thriving on the Doctoral Journey
}

\author{
Candice Satchwell, Hazel Partington, Lynne Barnes, \\ Ridwanah Gurjee and Susan Ramsdale \\ University of Central Lancashire, Preston, UK \\ csatchwell@uclan.ac.uk HPartington@uclan.ac.uk \\ lbarnes@uclan.ac.uk RGurjee@uclan.ac.uk \\ SLRamsdale@uclan.ac.uk \\ Jacqueline Dodding \\ University Centre Blackburn College, Blackburn, UK \\ j.dodding@blackburn.ac.uk \\ Kathryn Drury \\ Edge Hill University, Ormskirk, UK \\ Kathryn.Drury@edgehill.ac.uk
}

\begin{abstract}
Material published as part of this publication, either on-line or in print, is copyrighted by the Informing Science Institute. Permission to make digital or paper copy of part or all of these works for personal or classroom use is granted without fee provided that the copies are not made or distributed for profit or commercial advantage AND that copies 1) bear this notice in full and 2) give the full citation on the first page. It is permissible to abstract these works so long as credit is given. To copy in all other cases or to republish or to post on a server or to redistribute to lists requires specific permission and payment of a fee. Contact Publisher@,InformingScience.org to request redistribution permission.
\end{abstract}

This article explores the value of attending to the emotional side of the doctoral journey by focusing on the use of a 'secret' Facebook group amongst a cohort of EdD (Professional Doctorate in Education) students at one English university. Presented as a piece of action research in which the participants created an intervention to address a perceived problem and then reflected on its effectiveness, it is co-authored by the cohort of six students and their tutor. The stresses and loneliness of the doctoral journey have been well documented and constitute the 'problem' addressed by this cohort of students. Their inception and use of a Facebook group was a response to challenges experienced in their studies, with the expectation of facilitating peer support. As will be shown this aim was successfully met with enhancements in academic, social, and emotional support. However, unexpected benefits arose from the interactions within the group including a normalization of the challenges of the doctoral quest and the advantage of being able to follow the 'breadcrumb trail' found in the group postings as group journal and aid to reflection. Further, both tutors and students have noted the 
development of a strong sense of 'cohortness' and inclination to work collaboratively. Through a process of individual and group reflection on experiences of the intervention, combined with analysis of the content of the postings, this article examines the characteristics of the Facebook intervention and considers some ethical implications. We suggest that key characteristics that have contributed to its success include the student ownership, the protection of the secret format, and the combination of emotionally supportive, academic, and irreverent exchanges between group members. It is hoped that these insights may be useful to future doctoral candidates and their tutors as they negotiate their own way through the doctoral woods.

Keywords: Reflection, cohort, emotion, social, Facebook, support, secret, professional doctorate, education

\section{Introduction and Review of the Literature}

This article explores the value of attending to the emotional side of the doctoral journey by focusing on the use of a 'secret' Facebook group (Khare, 2011) amongst a full year cohort of six EdD students at one university in the North-West of England. The Doctorate in Education (EdD) at this university is a taught programme, using a closed-cohort model (Bista \& Cox, 2014). There are currently around 40 students enrolled on the programme, with an intake of approximately eight students per year. The participants in each year's cohort come into the university once a month, with occasional additional weekend meetings or workshops and some opportunities for cross-cohort interaction at joint workshops and conferences. The students study taught modules alongside reflective participant-led modules facilitated by tutors, at the same time as working on individual research and developing the final thesis with support from a supervisory team. This means that each group comes together relatively infrequently, and the opportunity for peer support is therefore also relatively infrequent, and the loneliness of the long-distance researcher (Gannon-Leary, Fontainha, \& Bent, 2011) can be inescapable.

This article is co-authored by one complete cohort of six students who have instigated the Facebook group and their tutor in an attempt at performing the collaborative nature of the topic we discuss. The students and tutor in this instance are all female, and although half the teaching team is male, there is a predominance of female students on the programme as a whole. While we do not address the factor of gender at length here, it is likely to have had an impact. Indeed, in keeping with this paper, there is 'a growing literature on female students' experiences of doctoral study which portrays emotion as an integral part of the process' (Aitchison \& Mowbray, 2013, p. 860). All authors have agreed to the use of first names and are aware that they are clearly identifiable as simultaneously authors of this article, EdD students, professionals, and contributors to a Facebook page. One member classified herself as predominantly an 'Observer' rather than a 'Sharer', but her reflection in the section on 'cohortness' makes clear that she is firmly established and fully accepted as a group member.

This absence of anonymity may appear ironic in the face of our assertion that the 'secret' nature of the group is paramount. However, this secrecy relates to the fact that the Facebook 'group' is closed and only members of it can contribute or view posts. Indeed, the tutor amongst the present authors has still not accessed the Facebook postings and feels that this would be a significant breach of the boundaries that have been especially constructed. This issue of 'identifiability' or 'anonymity' is also highly relevant to the topic of this article, in that the authors are all lecturers and aspiring academics as well as doctoral candidates. They, therefore, have conflicting identities as both students and professionals, and each of these identities has different needs and expectations. While research participants and students are entitled to confidentiality, academics have an increasing need to exhibit a public profile and to be named on publications. Exploring a way of fulfilling the requirements for both personal safety and academic endeavour is largely the subject of this article. 
Isolation of post-graduate students is commonly commented on (Ali \& Kohun, 2006; Pauley, 2004; Trujillo, 2007), although there is limited literature available examining the experiences of doctoral students. However, that which is available suggests that doctoral students frequently assume that they will become a part of a vibrant, supportive research scene, when in fact they are often disappointed in this belief and may even feel isolated in their studies (Janta, Lugosi, Brown $\&$ Ladkin, 2012). A review of the literature also shows an acknowledgement that different kinds of support are required for doctoral education. For example Brooks and Fyffe (2004) examine the use of online resources, Dabbagh and Kitsantas (2011) focus on the use of 'personal learning environments' to blend social and academic elements of the course, and Gannon-Leary et al. (2011) consider the benefits of a 'Community of Writers' in the context of lonely researchers engaged in academic writing. While these interventions touch on the social and emotional side of learning, they tend to be provided by institutions rather than led by students.

Hadjioannou, Shelton, Rankie, and Danling (2007), however, describe how student-led doctoral groups can create a dynamic supportive community, which provides its members with essential emotional sustenance (cited in Janta et al., 2012). The use and benefit of social networking sites to provide such learning spaces is also acknowledged (see for example Elllison, Steinfield, \& Lampe, 2007; Gray, Annabell, \& Kennedy, 2010; Selwyn, 2009). Derks, Fischer, and Bos (2007) reviewed studies of the communication of emotion in computer-mediated communication and concluded that 'social sharing' (p.5) can be just as successful on-line as face-to-face. The importance of socialisation in building on-line learning communities or 'communities of inquiry' is reinforced by Garrison (2011) and Preece (2000) who suggest that socialisation of learners can be a significant factor in both student retention and ultimately successful outcomes of their studies.

All of this supports the present authors' own experiences; however, here we explore the creation of a 'secret' space instigated by the students themselves outside of the institution, which seems to give the intervention its special identity. We consider the importance of the various strands of support that can be provided - and that seem to be needed by part-time doctoral students in particular.

Within the course, as exemplified by the learning outcomes, relationships between personal, academic, and practitioner aspects of self are frequently referred to as part of the EdD journey. The journey metaphor is well-worn (see for example, Batchelor \& Di Napoli, 2006; Fenge, 2012; Rockinson-Szapkiw, 2011). Its pertinence is partly because, for those who have completed a doctorate, there is a significant difference between the start and end-points with numerous obstacles to be negotiated along the way. This difference is not just in terms of qualification or status; it is also a deeply personal and emotional change. The experience of sharing with others these changes and this growth is in itself an expression of change and growth. This article will contribute to understanding how the social side of doctoral study can improve the quality of that journey in terms of personal, practitioner, and academic development. Recognising the different facets of ourselves and our various needs can help us to meet those needs. Recognising them in others can be reassuring and liberating in that we feel less alone, more connected, and therefore more able to continue on the journey.

\section{Methodology}

The literature and our own reflections have covered notions of individual and group identity, including student, academic, and practitioner identities. We have also addressed different kinds of support and uses of technology. A discussion about how to nominalise the topic of our paper highlighted methodological considerations. Are we most interested in the participants, the technology, or the function? While all of these aspects are relevant, we find the notion of an 'intervention' the most useful, carrying as it does an intimation of a methodology of action research. The students - who as it happens are all also lecturers - identified a problem (feelings of isolation 
on their doctoral course) and then devised an innovation to help them overcome the problem (a secret Facebook group) and to reach their goal (achieving a doctorate). The students then both individually and collectively reflected on the effectiveness of the innovation, which in turn both revealed and inspired further reflection in and on their postings on Facebook. As Newby (2014) explains, action research is particularly popular with educators because, "Action research embeds reflective practice in its processes. Reflective practice raises the question for action research to answer and may even determine the nature of the action" (p.630). Further, action research "is designed to improve outcomes and/or processes while, at the same time, enabling personal and professional development" (Newby, 2014, p.631). The EdD course is clearly designed to do just these things, and both the intervention and the writing of this article have contributed further to improving outcomes of the students' own educational development. While the authors have addressed a problem identified by themselves as students, the fact that these students are also lecturers, and the inclusion of their own tutor in the writing of this article, means that the 'usefulness' of the research is that it has implications for curriculum development both for the authors in their various contexts and for the readers of the article.

An initial group analysis of written and spoken reflections on the value of the intervention provided the themes of Support, Humour, Affection, Reflection, and Emotion, which conveniently made up the acronym SHARE. Further analysis of and reflections on the postings subsequently produced the headings presented here. A collaborative (sharing) process of re-writing, editing, and revision was then undertaken to such an extent that different reflective headings emerged, and the article became fully 'co-authored'. Our article is mainly reflective, synthesising perspectives from each writer, but using the framework of action research we first present 'the problem' and 'the intervention'.

\section{The Problem}

The production of a doctoral thesis is often referred to as a lonely affair (e.g. Janta, Lugosi, \& Brown, 2014). It requires concentration, focus, representation of one's self as a trustworthy researcher and academic, and also - when it is for a professional doctorate - practitioner. It means extensive periods of time grappling with concepts, complex texts, collecting data from the field, writing, and re-writing. By definition, most of these activities are done by oneself. For the students in this study, the research is usually carried out alongside holding down a full-time job in Higher Education.

This cohort of six began studying together on the EdD course in January 2013. Originally there were seven, but the one male member of the cohort moved to a professional doctorate programme within his own discipline. In some respects this event was a catalyst for the remaining students experiencing feelings of unease. Although they remained (and still remain) in contact with this member, the loss of one of the group appeared to both expose insecurities and encourage bonds to form. Several months into the doctorate, the group began to experience difficult times: some were still in the process of refining research proposals or applying for ethical approval, others had tentatively begun their research fieldwork, and all were working to complete assignments and trying to balance the demands of doctoral studies with work and personal lives. Classes were once a month and, whilst the cohort apparently worked well together and were beginning to get to know one another, it seemed that it was easy to lose touch in between sessions, leading to feelings of isolation and struggle.

Doctoral study is intense by its very nature and the doctoral candidate often runs the whole gamut of emotions during the process due to the personal investment in the research (Burgess, Siemenski, \& Arthur, 2006). During the professional doctorate this is further intensified as professionals are investigating their own professional practice, ensuring that feedback from the course team on submitted work is sometimes met with an inordinate amount of dismay (Aitchison \& 
Mowbray, 2013). Doctoral candidates often feel that feedback is a very personal criticism of their abilities, and this, once more, can create feelings of isolation and questioning of knowledge and skill (Cox, Carr, \& Hall, 2014).

The group members have professional identities; between them they hold senior or principal lecturing positions, teach undergraduate and postgraduate students, support and guide students through dissertation and Master's level study, give conference papers, and undertake national and international consultancy work. It is therefore not easy to admit to feelings of inadequacy, of an inability to write or to understand, of frustration at course materials and assignment briefs, or of marking criteria and deadlines, especially where the doctoral supervisors are university colleagues. The group felt the need for a safe space in which to offset the emotions that could not comfortably be displayed in class; somewhere for the students to feel comfortable and confident enough to share their lack of confidence.

\section{The Intervention: Evolution of the Facebook Group}

As a senior lecturer who worked with e-learning students, one of the group had previously looked into the use of social media as an aid to socialisation and knew of the potential advantages of a Facebook group, including the familiarity and ease of use for many students, the scope for creativity, and the ability to foster a sense of belonging and exploration of identity (Mason \& Rennie, 2008).

She felt that a Facebook group might offer the students a way to enhance their social processes and to facilitate and strengthen peer support (Brooks \& Fyffe, 2004). There were also potential drawbacks, however, for example with issues of boundaries and confidentiality and the realization that not everybody might be keen to join such a group (Beninger et al., 2014; Lupton, 2014; Mason \& Rennie 2008). As professional people it felt essential to set the group up as secret; nobody but members could see the group's existence or any of the postings. The initial implicit agreement of confidentiality within the group enabled a sense of trust and security to develop, but the secret nature of the group was also a significant factor in the way the students regarded it as a safe space, ensuring that its members knew where they could turn to for support in any circumstance.

The original purpose was to offer a space in which to "vent, sympathise, and share our triumphs and disasters" (Hazel on 25.10.13). However none of the group at the outset foresaw the additional benefits that it would afford the cohort as use of the group evolved over time. As Hazel reflected later:

"Scrolling through the posts provides a group journal - it reminds us of the triumphs and disasters, the story of our journey - it's like our breadcrumb trail through the woods. I didn't expect that messing around on Facebook would provide an aid to reflexivity, I didn't see that one coming!"

The importance of reflection and professional learning is examined in the next section, followed by the group's reflections collected together under four broad headings.

\section{Academic Reflection and Professional Learning}

For all members of the group, reflection is a vital and purposeful activity, giving momentum to their learning and their continuing evolution as educators and doctoral candidates (K. Williams, Wooliams, \& Spiro, 2012). Brookfield (1995), writing of the importance of critical reflection for educators, identifies four interconnected lenses which may facilitate or trigger reflective processes: the autobiographical lens, the lens of students' perspectives, the lens of colleagues' perspectives, and the lens provided by perspectives drawn from the literature. 
According to King (2011), “An individual's use of social media as professional learning spans understanding, networking, professional identity development and transformative learning" (p.40). While each individual might use social media for different ends, both as professionals and in their personal lives, one of the unpredicted benefits of the secret EdD Facebook group was that it could function as an aid to reflection on the collective and individual doctoral experiences. Further, when reviewing the postings, each person engages with both collective and individual autobiographical lenses. The various and seemingly random musings, cries for help, jokes, requests for information, and expressions of triumph not only provide a breadcrumb trail through the woods, but also provide an opportunity to reflect on that journey.

The facility for reflection within the group appears to work on two main levels: on-the-spot, surface reflection, often taking form as ironic, self-affirming, or self-deprecating declarations (or sometimes a combination thereof); and the deeper more considered reflections arising from reviewing and revisiting the trail of postings which engages with the autobiographical lens (Brookfield, 1995).

Shades of the ironic may be found in Susan's posts referring to reflection, where she plays with the concept of reflection and in doing so reflects on her own reflective processes and the resulting impact on her evolving and multiple identities:

'”On reflection, I have lost the will to live" (Susan, 12.1.14)

or

"I have done so much reflecting on professional, academic and personal self, I no longer know who I am!" (Susan, 11.3.14)

A further example combining irony and self-deprecation can be found in Hazel's 'rant' prior to preparing for a critical discussion to be presented in class, in which she expresses frustration with the difficulties of balancing assignments and fieldwork, and reveals feelings of inadequacy when assessing progress so far.

"So I started looking at what we have to do for the critical discourse on 25th and it seems that my talk will be very short and will consist of 'I have hardly done any research because I am busy doing assignments. I don't have a clue about impact, significant contributions to practitioner knowledge or change theory because I am too busy doing assignments. I don't know what the foundations and rationale behind my research are anymore because I have been too busy doing assignments and have forgotten what I said in the first place.' Can you base some good questions on that Lynne?

It's a good job we didn't do this in June; I'd have had even less to say then!" (Hazel, 31.8.14)

However, being able to address feelings of inadequacy in a safe space and receiving 'mirroring' comments from peers allowed Hazel both to reflect on her achievements to date and also to realize that she could address feelings about the assignment load within her presentation.

Lynne's post a few days later about the same critical discussion assignment also demonstrates self-deprecation: by describing her draft discussion as 'Jackanory' (a children's television storytelling programme) she is reflecting on her sense of not having anything important to say at this stage in her journey.

"I've started the critical discussion - but am at a loss. Is anyone using theory here and how? In 7 minutes? 
I am trying to answer the Learning Outcomes but my discussion is looking like Jackanory ... i.e. just a story of where I am up to - and the fact that I don't have anything significant yet to say. Any advice?" (Lynne, 17.9.14)

The response from the group here showed a resonance for many: the term 'Jackanory' provided a commonly agreed metaphor for the discussion scripts, but also, engaging with the lens of colleagues' perceptions, helped the group members to see that their position in the research process was appropriate and acceptable.

Self-affirming postings within the group are often simple declarations of achievement, as in "I've got data" or "I've submitted my assignment", not necessarily including reflection; however, on occasions a reflective tone can be detected as in Susan's post about her first forays into thematic analysis where her postscript expresses her enjoyment of the process and her surprise at that enjoyment:

"Wow just applied a little thematic analysis (I think) to first interview in readiness for next assignment! Would have been nice just to be able to do more analysis rather than consider the essay. However, the weekend calls so everything shelved. There's always next week. Have a good week end $x$

PS actually enjoyed it but don't tell anyone!'”(Susan, 15.8.14)

As can be seen, within these postings reflection has been with a light touch. However when three of the group decided to collaborate on a poster presentation about the benefits of the Facebook intervention in facilitating peer support, they discovered that sifting back through the posts in order to code them became a reflective and reflexive process in which they were able to see their identities as doctoral candidates and researchers evolving and growing. For example, Hazel was surprised to realise that when she wrote:

"Tying myself up in Foucauldian knots - why do I keep going deeper and deeper when I was nearly finished?" (Hazel, 22.2.14),

although using a joking tone she was also establishing her scholarly identity. The sub-text was "I am a scholar and a researcher who is trying to engage with difficult concepts." Looking back at another post reveals uncertainty about the significance and value of individual research:

"Anyone else suffer from project envy? I was talking to two people today who are doing doctorates, one was doing the temporal perceptions of online students, and the other was looking at the assessment of competences in social workers. They both sounded much more important and interesting than mine." (Hazel, 10.12.13)

Yet, a year on from this, it is clear that progress has been made with fieldwork, and Hazel is feeling more confident of her own contribution.

As the concepts of personal and professional identity feature strongly in professional doctoral research, the facility to review postings within this group and to compare them to entries in reflective journals has provided the students with an invaluable - and unpredicted - tool with which to monitor and track their own multiple and evolving identities as educators, doctoral candidates and researchers (Fenge, 2010). An important aspect of the reflective and reflexive process for practitioner researchers is to understand one's professional self in relation to one's personal self (Costley, Elliot, \& Gibbs, 2010); collectively examining the postings in the Facebook group has given the group a further tool for understanding themselves and each other and for forging a strong group identity. This, in turn, strengthens all of their individual identities as doctoral candidates and researchers. 


\section{Reflection 1: Bonding of the Group - The Value of 'Cohortness'}

Although many prospective doctoral students look forward to engaging with a supportive academic community, this group appeared to have few such expectations. As Susan wrote:

"When I began my doctoral journey, I really didn't see a breadcrumb trail through the woods. It seemed to me more like being parachuted into a jungle with only a penknife to cut through the tangle of vegetation. I saw a dark and lonely path ahead, filled with obstacles and setbacks; a perception fuelled by doctoral folklore and backed up by colleagues undergoing or recently ending their own doctoral journeys".

Therefore the group's experience has been 'surprising', an epithet each member has applied in their reflection on the success of the group. Jacqueline, for example, states:

"It was a surprise, therefore, from the outset, how the cohort became a cohesive, supportive whole, and the introduction of the Facebook group, during a difficult time for the students, only cemented this and allowed our group to become ever more supportive of each other";

and Susan concludes:

"So how is it that two years into this cold and lonely journey I am actually really enjoying it and have completely banished these dark images and replaced them with scenes of pleasure and laughter? The obstacles are still there but I view them as challenges that I will overcome, not as a single combatant, but as part of an eager band bound by commitment, a sense of community and not least through laughter."

Their experience concurs with Fenge (2012) and Bista and Cox (2014) that 'cohortness' is key to a successful professional doctorate journey. We suggest that the support offered among the doctoral colleagues in this Facebook group has enhanced the cohort identity (Fenge, 2012): each knows what is happening in others' lives external to the doctoral process, and such knowledge allows the group to be caring on both an academic and a personal level. Whatever one of the members is undergoing, the others are party to it if they post on Facebook and therefore can be supportive in many ways, whether it is a good or bad experience. This type of behaviour is typically described as 'mutually empowering' (Fletcher, 1995), where members of the group are "keen to demonstrate genuine care for others and proactively avoid conflict" (Devenish et al., 2009).

It is significant that the relative non-user of the group also considers herself to have benefited from the group membership. Her own perspective on Facebook generally is that it is unwieldy and overwhelming, and her limited experience fuels her lack of engagement. Regarding herself as an 'Observer' (with some 'Sharer' characteristics) (as defined by Beninger et al., 2014), Ridwanah (known as Riz) has made only seven posts, mainly to demonstrate support or to share information, for example:

"Just catching up on all your comments, ha ha, u guys $r$ ace!x" (6.12.13)

"I am teaching [...] 2moz and I will miss the session. Will c u all afta 4pm" (22.1.14)

However, Riz describes an experience in a face-to-face meeting, which demonstrates the farreaching beneficial effect of the Facebook group:

"I feel that my lack of engagement with the site has not made me feel isolated from my peers in any way. We are a very close-knit team with the shared experience of completing a doctorate and there are many times when I have received advice and felt extremely supported by my colleagues; for example, a recent revision of a data analysis paper was completed through the support and encouragement of my doctoral peers. They picked up 
on my low levels of enthusiasm and kindly stayed behind past 6pm after a long day's workshop to give me direction on how best to make improvements and boosted my motivational levels. I was very much overlooking the positive feedback that I had received and my peers were central in helping me recognise the many good comments on my work. This would not have been possible if we did not have this sharing and caring ethos cultivated by the Facebook group."

Beninger et al.'s (2014) finding that social media helps facilitate rather than replace in-person contact appears to be borne out by this experience. The bonding that has occurred through the use of Facebook is reflected both within facilitated workshops and in social interactions outside of the academic environment.

\section{Reflection 2: The Benefits of Peer Support}

If we accept the definition of support as "to bear all or part of the weight of; to hold up" ("Support," 2015), we can see by reflecting on the posts in the Facebook group that members have employed different means of "holding each other up" and preventing each other from falling - frequently through humour and by showing affection. Support has been provided for different ends: to support academic endeavour or emotional unease, to provide practical assistance, or to empathise as a peer. Although the initial intention may have been to provide emotional, practical, academic, or peer support, the posts usually transformed into humorous expressions of encouragement and empathy, signalling that the problem could be overcome:

Jacqueline: Well here goes... One day to write my presentation... Done the reading now just need to sort it out in my head - Could get messy!

Hazel: You can do it Jacqueline! May the force be with you.

Susan: Go Jacqueline You'll ace it!

Hazel: [X] will be missing such a treat listening to our ramblings, sorry erudite discourse in policy.

[Later]

Jacqueline: We are all exhausted -post traumatic presentation disorder!

Lynne: That's what I'm feeling ... Post traumatic presentation disorder! Like it... Will wine remove the symptoms?

(April 2014)

Within this example can be seen something of the difference between the support offered from the course team and that from peers. The students, in this safe Facebook environment, are able to express emotions which they know will be shared by their peers. Jacqueline explains:

"Personally, it was a relief for me to know that other people were experiencing difficulties with ethical procedures, assignments, time limitations, data collection, and more, but I believe we all were relieved when we began to understand that we were all undergoing a collective experience and could empathise and support one another throughout."

The Facebook group offered and continues to offer a safe, informal, non-competitive space. This stands in contrast to other alternatives, such as formal discussion boards available on the university's virtual learning environment where students often feel there is a sense of rivalry among their cohort as they endeavour to intelligently answer posed questions and comment in a competitive way since they are in the public domain (Aitchison \& Mowbray, 2013). 
The Facebook intervention has had the effect of diluting negative feelings for this cohort, as they are able to vent feelings, thoughts, and worries to the group, without fear of reprise or sarcasm. In fact, the opposite is true: although members may feel upset or angry at times with the doctoral process, the other group members' supportive insistence that "we are all in this together and will all pull each other through" is both impressive and very reassuring. No one will sink, because the other members will be there to prevent it. As Devenish et al. (2009) explain, a study group encourages its members to "keep going, to reinforce that the studies are worthwhile and that completion is an attainable goal" (p.61). One of the ways this group has kept such encouragement going is through emotional support, with a specific emphasis on humour.

\section{Reflection 3: The Value of Emotional Support and the Importance of Humour}

Whilst there are multitudinous theories of emotion (see, for example, Denzin, 2009; Strongman, 2003), the concept most relevant to the emotional journey we describe is that of emotional labour. This was first defined by Hochschild in 1983 in relation to service workers who need to maintain emotional responses appropriate to the service users with whom they are interacting and is later encapsulated by Aitchison and Mowbray (2013) in their research into emotional management amongst female doctoral students. Emotional labour can be defined as when one disguises and suppresses one's true feelings and puts on a 'public face' that all is well. In reflecting upon this female cohort journey through the doctorate via social media, it is possible to see that the Facebook site is frequently used to express emotions that remain hidden during taught - or even facilitated - classes.

The emotional themes coming from the posts can be classified in many ways, but largely they fall into the following categories:

- frustration at things not going right, at an inability to write, to understand, to get on with it

- fear that others are doing better, collecting more data, beginning transcription; of being left behind

- guilt at not spending enough time studying, undertaking fieldwork and writing juxtaposed with the ever-present conflict with work pressure, the changing, unsettling HE climate and general family life of birthdays, births, deaths, and holidays

- anger at tutor feedback, a perceived lack of direction, a lack of clarity

- confusion at not knowing what was supposed to be done, by when, and how

- joy and (a shared) celebration at getting the work completed, the data collected, the transcription finished, the essay passed

- affection; a sharing of ' likes', smiley emoticons, photographs, and metaphorical pats on the back.

Lynne readily admits to using the Facebook group as "a huge emotional crutch". A typical comment from Lynne reflects a number of the above themes: a fear of being left behind, that others know what they are doing, a plea for moral and literal support:

'Ok guys, now I'm panicking! No idea what I am meant to be doing or for when :-( Seriously behind on all things EdD. Can we meet up?'(Lynne, 7.1.14)

On reflection Lynne realises that many of her comments reveal similar doubts: despair at not being able to submit work on time, inability to engage with an assessment, needing reassurance. In return came encouragement, motivation, and a vindication of her ability to complete the task. This resonates well with research undertaken by Selwyn (2009) with 909 students using Face- 
book for educational use. He discusses supplication and the seeking of moral support as being a major theme:

"Students would often present themselves as rendered helpless in the face of their university work in the expectation that their peers would offer them support and comfort." (p.167)

Whether or not this was the subconscious strategy, it appears to have worked, for Lynne and for the rest of the cohort. Clearly, they share emotions as a means of motivation. This might be all the more meaningful and significant because they see each other only once a month and need not only encouragement to keep them on track, but congratulations and a recognition that they have managed to do doctoral study in the midst of competing demands:

“'Well done Hazel! Just going to shout this, NOT STARTED YET!! .. Enjoy your feeling of satisfaction, I will take inspiration from you” (Susan, 17.7.14).

The development of the Facebook group enabled the cohort to communicate with each other and engage in banter "as though we were actually talking to each other" (Susan). This is an interesting perception as a positive characteristic, as often online forums are seen as beneficial for some students precisely because they avoid face-to-face contact (e.g., Cox et al, 2004) and provide an 'anonymous' space for students to contribute to a discussion.

When considering academic views on building resilience it is evident that humour is seen as a key component. Humour is defined as a general positive attribute and is one of the character strengths that contribute most strongly to life satisfaction (Peterson, Ruch, Beermann, Park, \& Seligman, 2007). Looking at a small selection of the group's posts we can see how, by the use of what Kuiper (2012) describes as affiliative humour, a warm, witty but respectful banter, the use of Facebook has enhanced this group's cohesiveness and morale and has itself developed into a positive presence within the group. A typical post would involve cries of panic about feeling unable to grasp the learning outcomes for an assignment or even feeling unable to begin to write. This is an excerpt from a post concerning the writing of a literature review:

Susan: "Hi Gang, finally made a start on lit review! 375 words - not that I am counting and already, on reflection, have lost the will to live! It's going to be a long day $x$ "

Lynne: "Just realised that in order to write a literature review, you should first have read something? Oh God!!! xxx"

Hazel: "You gonna reflect on that Lynne? How is the literature affecting you? It's making me read...I think that would go down well don't you?" (05.07.14)

What at first seems like just a few words of banter can in fact be seen to be a very supportive discussion; the humour in 'not that I am counting' and 'lost the will to live' acknowledge the stress of trying to even begin an essay and imply a request for sympathy. The supportive response, with the comforting implication, "You are not alone", and the joke about reflection bring everything into perspective - it is an essay, not the end of the world.

As the group began to prepare their assignments relating to methodology, Hazel posted a semiserious question:

"When discussing methodological choices is it acceptable to say I decided not to do this because it looks too hard?"

Kathryn: "I think that would be OK as long as you made it sound reflective lol."

Jacqueline: "I'd definitely say yes (-)"

Susan: "Yes. Definitely! I'm thinking along the same lines! X" 
Hazel: "Not that I'm writing you understand, just thinking about it @)” (05.07.14)

Again the posts begin with a request for help, and again the responses work in a light-hearted fashion to normalise the situation, i.e., all the group are in the same position and therefore it is 'OK'. Reference is made to general feelings of inadequacy and hesitancy in embarking on assignments, and again encouraging responses appear that help to put this into perspective. The use of humour within the group's postings clearly confirms Kuiper's (2012) findings that affiliative humour supports the development of group cohesion and support. As Windle (2011) suggests, a sense of humour is one of the most important facets of personal resiliency that an individual can draw on when confronted with stress.

So, reflecting on the use of humour within the Facebook group it is clear that it has played a major part in sustaining and developing the cohort. It has enabled the creation of a distinct and vibrant identity within the doctoral programme, a group that is now renowned to be enthusiastic and happy and who will laugh and work together to find a solution rather than cry and withdraw in isolation.

"It has seen us through some quite dark times but more than that, it has banished those dark times to a distant memory and for me, the forest is now full of opportunity and good natured company." (Susan)

\section{Reflection 4: Academic Endeavour and Social Support: A Balance}

A need for support is most clearly evident in the Facebook group when individuals have received feedback on assignments and presentations. Academic feedback is not always perceived as positive, and the Facebook group is seen as a place to vent frustration and receive emotional support. While a positive supportive response is evident in the interactions, there is also a realistic engagement with the feedback received and its potential to assist development. Rather than a universal rejection of the feedback, there is encouragement to engage with it and offers of help from other members of the group who have fared better. Kathryn reflects:

"I have found this particularly useful, as confirmation of my initial negative feelings would only have limited my engagement with the feedback and further prevented me from valuing comments aimed at my development. The responses from the group recognise the effect of the feedback and the resulting expression of emotion but avoid the establishment of a reversal of the 'halo effect' where individuals receive only confirmation of their own frustrations."

The affectionate yet challenging support that is evident in the Facebook group is what distinguishes the use of social media to support academic study from the use of social media in general and, also, from a more conventional academic online forum. A typical comment, which incorporates encouragement, advice and offer of further support, is:

Susan: "Of course you can do it but I think there is some good advice on the earlier comments. Try to look at it in bite size chunks and do a bit at a time. Want to meet up soon?"

There is a need in academic study for analysis and reflection that results in interactions that engage emotions differently from within purely social interaction. When expressing disappointment within a social environment there is the expectation that other participants will concur and confirm individual experiences; whereas within an academic support group there will be critique and analysis. The key to continued engagement in this Facebook group appears to be that useful critique is given but within an affectionate, supportive framework. Yet the participants also appreciate the 'mirroring' comments they receive which have the function of reassurance. 
A highly positive aspect of the Facebook group is being able to celebrate academic success, where, especially following disappointment, an emotional response is warranted:

Kathryn: "Passed my resubmitted lit review Yayyyy. So back on track. Now need to get my head around what I am supposed to do next!!!!"

Hazel: "Hooray!"

Jacqueline: "Well done! $X$ ”

Lynne: "Well done. Not done mine yet ..."

Lynne's admission of inadequacy in this context both contributes to the group cohesion and offers up a request for confirmation that she too might need emotional support.

It is this realistic, grounded, 'we are all in this together' approach that has cemented the group together and kept each individual using it as they have pulled and pushed each other along the doctoral pathway.

\section{Discussion}

As we have said, a great deal of the literature detailing doctoral education uses the metaphor of a journey. In re-reading the Facebook posts from 2013, in a linear and chronological sequence, it is very much evident that this is indeed a journey. It is easy to chart the emotional experience of the doctoral process along a series of outpourings largely related to anxieties surrounding assignments and confusion compounded by academic discourses and unfamiliar literature. In reviewing the past eighteen months via a frozen capture of questions, expressions of despair, congratulations on a job well-done, pleas for help and the ever-present 'thumbs up' emoticon, it is apparent how emotional the journey has been so far, and how the social media space has become a sanctuary for emotional expression and, perhaps more importantly, emotional support.

In this piece of action research the students have addressed "a felt need ... to initiate change" (Elliott, 1991, p.53) by creating a space in which to communicate with one another on a regular basis in a different context and space from the academic/work-based setting. It is a collaborative space, rather than an individual writing space, and it allows conversation on a variety of themes. While the individuals are brought together by their academic ambition, the virtual space enables a combination of academic, social, and personal issues to be discussed, shared, offloaded, and explored. The eclectic nature of the posts highlights the multiple identities of the participants - as academics, teachers, nurses, practitioners, students, etc. - but also as parents, friends, and individuals with their own complex lives. We suggest that this specific 'secret society' use of Facebook allows these aspects of self to intermingle and inform one another, but in a different way from more usual uses of Facebook. The social space enables communication on different levels, while also contributing to the original purpose of the group, i.e., completing their doctorate.

We have identified several characteristics of this intervention that contribute to its success. One of these is the 'secret group' setting. While some (e.g., Barnes, 2006) have identified a fear of intrusion into one's private life due to the public nature of social media platforms and the potential risk of sharing online content, some professionals are using social networking in educational contexts and consider it to be important for student development (Davis, 2010). The choice to make the EdD group secret obviates these risks but also differentiates the group from other uses of Facebook, either academic or social.

The spontaneity of the group's development as such suggests that it is a true requirement of the students and one that they have defined themselves. We suggest that the student-initiation element is crucial to its success, in that it is truly 'student-centred' and exclusive. As the participants have pointed out, there is no competitive element to the posts; there is also no surveillance from 
tutors. Attempts have been made at institutional level to introduce VLE spaces to encourage social interaction on this course as well as many others. However, the scenario of the unpopulated discussion forum is familiar to many tutors, and the forum provided by tutors for students on this EdD programme is little different. B. Williams (2013) explains that "digital media, by themselves, do not make the contemporary university a more participatory and creative educational space" and further makes the point that, conversely, VLE systems actually work "to reinforce traditional conceptions of the university as hierarchical, controlling, print-based, and obsessed with assessment" (p.182). The characteristics of the Facebook intervention are the opposite of these; and unlike a formal academic forum, continued use and engagement in this group is dependent on the usefulness it has for them as individuals.

We are also given insight into the impact of Facebook interactions on face-to-face relationships. It is clear that the group works as an extension of a face-to-face group; it is doubtful that it could be effective as the only means of communication, but it is rather a supplementary resource. These part-time professional doctoral candidates might be considered to have a particular need for this supplement, in that they are not full-time students located in departments or faculties with other $\mathrm{PhD}$ students with access to research groups and their facilities. However, it also seems that this use of social media has impacted positively on how they interact as a group, to the extent that the relative 'non-user' of the group also benefits from the inclusivity it engenders. Terms that are repeated in these students' descriptions of the Facebook group include safety, empathy, and familiarity, along with the original headings of Support, Humour, Affection, Reflection, and Emotion. Ultimately the acronym SHARE sums up the value both in terms of its constituent elements and the notion of 'sharing' in its own right. It seems to be the egalitarian, non-judgmental, giving, and receiving in equal measure that contributes to the success of the group. The use of 'we' in some of the posts, such as "We are all exhausted" and "We are a great group" is truly inclusive, rather than the pseudo-inclusive 'we' as often employed by teachers. The tutors for these students can never genuinely include themselves in synchronous reflection on the experience of the doctoral journey. The inclusivity and equality that arise from using this medium to share the lived experience of the group is what lends the Facebook group its effectiveness as an emotional tool. The sharing can only really be undertaken by members of the group who are experiencing the same journey at the same time, with comparable reactions to the demands and challenges of that journey.

\section{Conclusion}

The Facebook intervention introduced in order to address the problems of isolation, loneliness, and academic challenges has been successful in overcoming these negative phenomena. All six of the students are currently writing up their theses and comprise the first cohort to have completed all assignments without recourse to extensions on deadlines. They continue to communicate as a group using their Facebook intervention for support during the potentially isolating phase of individual writing-up.

As a piece of action research the project has had the benefit of providing insight for the participants that, as practitioners in education, it is crucial to pay attention to the emotional aspects of learning. To celebrate the success of the intervention, the EdD programme provides the opportunity for existing candidates to inform new recruits of strategies that have helped them. This has inspired other groups to design and implement their own interventions, the outcomes of which are yet to be seen.

Perhaps the significance of this Facebook intervention is most relevant for other students on similar programmes, i.e., part-time, professional doctorates. All the same, there are implications here for the value of student-led networking, and some indications of what might make it successful. One of our conclusions must be that the group ought not to be tutor-led, nor even tutor- 
influenced. Its secret, irreverent nature, which excludes outsiders, itself gives rise to the inclusivity within the group that has been so productive. While the posts quoted here might appear trivial and inconsequential, the writers have been surprised by the value of the group, surprised by its usefulness as a reflective tool, and surprised by how much they have enjoyed being a part of it and how this has been reflected in their academic engagement. The relevance of irreverence should not be underrated. As one participant said, "The doctorate is really serious. This isn't", and yet the humour and affection expressed has had an effect of normalisation, providing a safe place of hidden depths. The knowledge that there is recourse to this safe space has been enabling in that no-one has given up or fallen down: they have all supported one another over and around the obstacles, laying down for one another the breadcrumb trail that will eventually lead them out of the woods. The production of this article has been an extension and manifestation of the characteristics of the group, albeit with the concession of allowing a tutor to collaborate.

\section{References}

Aitchison, C., \& Mowbray, S. (2013). Doctoral women: Managing emotions, managing doctoral studies. Teaching in Higher Education, 18(8), 859-870.

Ali, A. \& Kohun, F. (2006). Dealing with isolation feelings in IS doctoral programs. International Journal of Doctoral Studies, 1, 21-33. Retrieved from http://www.ijds.org/Volume1/IJDSv1p021033Ali13.pdf

Barnes, S. B. (2006). A privacy paradox: Social networking in the United States. First Monday, 11(9), 20.9.15.

Batchelor, D., \& Di Napoli, R. (2006). The doctoral journey: Perspectives. Educate, 6(1), 13-24.

Beninger, K., Fry, A., Jago, N., Lepps, H., Nass, L., \& Silvester, H. (2014). Research using social media; Users' views. London: NatCen Social Research.

Bista, K., \& Cox, D. (2014). Cohort-based doctoral programs: What we have learned over the last 18 years. International Journal of Doctoral Studies, 9, 1-20. Retrieved from http://ijds.org/Volume9/IJDSv9p001-020Bista0425.pdf

Brookfield, S. D. (1995). Becoming a critically reflective teacher. San Francisco: Jossey-Bass Higher and Adult Education.

Brooks, C., \& Fyffe, J. (2004). Are we comfortable yet? Developing a community of practice with PhD students at the University of Melbourne. Beyond the Comfort Zone: Proceedings of the 21stASCILITE Conference, 163--169.

Burgess, H., Sieminski, S., \& Arthur, L. (2006). Achieving your doctorate in education. London: Sage.

Costley, C., Elliott, G., \& Gibbs, P. (2010). Doing work based research: Approaches to enquiry for insiderresearchers. London: Sage.

Cox, G., Carr, T., \& Hall, M. (2004). Evaluating the use of synchronous communication in two blended courses. Journal of Computer Assisted Learning, 20, 183-193.

Dabbagh, N., \& Kitsantas, A. (2011). Personal learning environments, social media and self-regulated learning: A natural formula for connecting formal and informal learning. Internet for Higher Education. Doi: $10.1016 / j$.iheduc.2011.06.002

Davis, M. R. (2010). Social networking goes to school. Education Digest, 76(3), 14-19.

Denzin, N. K. (2009). On understanding emotion. (2nd ed.). New Jersey: Transaction Publishers.

Derks, D., Fischer, A., \& Bos, A. (2007). The role of emotion in computer-mediated communication: A review. Computers in Human Behaviour. DOI: 10.1016/j.chb.2007.04.004

Devenish, R., Dyer, S., Jefferson, T., Lord, L., Van Leeuwen, S., \& Fazakerley, V. (2009). Peer to peer support: The disappearing work in the doctoral student experience. Higher Education Research and Development, 28(1), 59-70. 


\section{Breadcrumb Trail through the Woods}

Elliott, J. (1991). Action research for educational change. Milton Keynes: Open University Press.

Elllison, N. B., Steinfield, C., \& Lampe, C. (2007). The benefit of Facebook 'friends': Social capital and students' use of online social network sites. Journal of Computer-Mediated Communications, 12(4), $1143-1168$.

Fenge, L. (2010). Sense and sensibility: Making sense of a professional doctorate. Reflective Practice, $11(5), 645-656$.

Fenge, L. (2012). Enhancing the doctoral journey: The role of group supervision in supporting collaborative learning and creativity. Studies in Higher Education, 37(4), 401-414.

Fletcher, J. K. (1995). Radically transforming work for the $21^{\text {st }}$ century: A feminist reconstruction of 'real' work. Academy of Management Journal, (Best Paper Proceedings), 448-452.

Gannon-Leary, P., Fontainha, E., \& Bent, M. (2011). The loneliness of the long-distance researcher. Library HiTech, 29(3), 455-469.

Gardner, S. (2007). 'I heard it through the grapevine': Doctoral student socialisation in chemistry and history. Higher Education, 54(5), 723-740.

Garrison, D. R. (2011). E-learning in the $21^{\text {st }}$ century: A framework for research and practice. London: Routledge Falmer.

Gray, K., Annabell, L., \& Kennedy, G. (2010). Medical students' use of Facebook to support learning: Insights from four case studies. Medical Teacher, 32, 971-976.

Hadjioannou, X., Shelton, N., Rankie, R., \& Danling, D. (2007). The road to a doctoral degree: Cotravellers through a perilous passage. College Student Journal, 41(1), 160-177.

Hoschild, A. R. (1983). The managed heart: Commercialization of human feeling. Berkeley CA: University of California Press.

Janta, H., Lugosi, P., \& Brown, L. (2014). Coping with loneliness: A netnographic study of doctoral students. Journal of further and Higher Education, 38(4), 553-571.

Janta, H., Lugosi, P., Brown, L., \& Ladkin, A. (2012). Migrant networks, language, learning and tourism employment. Tourism Management, 33(2), 431-439.

Khare, P. (2011). How to use secret Facebook groups to enhance your business. Retrieved 22 September 2015 from http://www.socialmediaexaminer.com/how-to-use-secret-facebook-groups-toenhance-your-business/

King, K. (2011). Professional learning in unlikely spaces: Social media and virtual communities as professional development. International Journal of Emerging Technologies in Learning (iJET), 6(4), 40-46.

Kuiper, N. (2012). Humor and resiliency: Towards a process model of coping and growth. Europe's Journal of Psychology, 8(3), 475-491.

Lupton, D. (2014). 'Feeling better connected': Academics' use of social media. Canberra: News \& Media Research Centre, University of Canberra.

Mason, R., \& Rennie, F. (2008). E-learning and social networking handbook: Resources for higher education. New York: Routledge.

Newby, P. T. (2014). Research methods for education (2nd ed.). London: Routledge.

Pauley, D. (2004). Group therapy for dissertation-writers: The right modality for a struggling population. Journal of College Student Psychotherapy, 1, 25-43.

Peterson, C., Ruch, W., Beermann, U., Park, N., \& Seligman, M. E. P. (2007). Strengths of character, orientations to happiness and life satisfaction. The Journal of Positive Psychology, 2, 149-156.

Preece, J. (2000). Online communities: Designing usability, supporting sociability. New York: Wiley.

Rockinson-Szapkiw, A. J. (2011). Improving doctoral candidates' persistence in the online dissertation process. Proceedings of Global Learn Asia Pacific, 1162-1166. 
Selwyn, N. (2009). Faceworking: Exploring students' educated-related use of Facebook. Learning, Media and Technology, 34(2), 157-174.

Support. (2015). In Oxford English Dictionary. Oxford: Oxford University Press.

Strongman, K. T. (2003). The psychology of emotion: From everyday life to theory (5th ed.) West Sussex: John Wiley \& Sons.

Trujillo, C. A. (2007). Building internal strength, sustainable self-esteem and inner motivation as a researcher. Journal of Research Practice 3(1), 1-9.

Williams, B. (2013). Control and the classroom in the digital university: The effect of course management systems on pedagogy. In R. Goodfellow, \& M. Lea (Eds.), Literacy in the digital university (pp. 173183). London: Routledge.

Williams, K., Wooliams, M., \& Spiro, J. (2012). Reflective writing. Hampshire: Palgrave MacMillan.

Windle, G. (2011). What is resilience? A review and concept analysis. Reviews in Clinical Gerontology, $21,152-169$.

\section{Biographies}

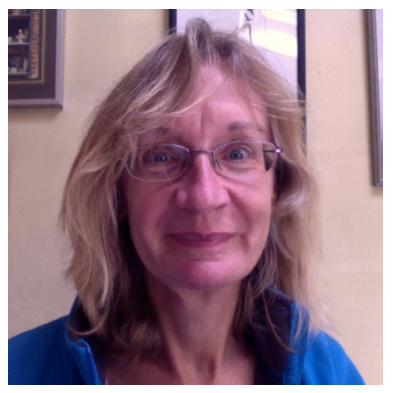

Candice Satchwell is Course Leader for the Masters and Doctorate in Professional Practice in Education at the University of Central Lancashire. Candice has taught in Further and Higher Education since 1992, predominantly as a lecturer in English and Linguistics. She has carried out research in a variety of educational settings, including schools, Further Education Colleges, and universities. She has several recent and forthcoming publications in the areas of education and literacy studies. Candice is currently leading a large AHRC-funded project Stories to Connect With: disadvantaged children creating 'phygital' community artefacts to share their life-narratives of resilience and transformation (2015-2017 www.stories2connect.org )

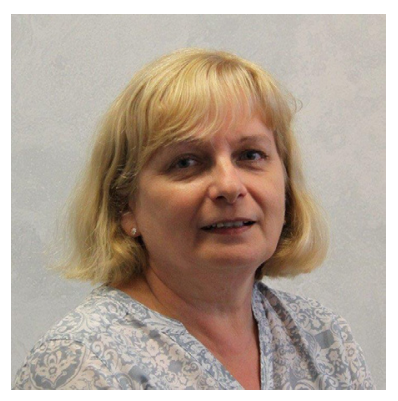

Hazel Partington (MSc FHEA RSHom), College of Health and Wellbeing, University of Central Lancashire, has been teaching in the health field since 1999. She is a senior lecturer teaching on MSc courses delivered via e-learning to traditional and complementary medicine $(\mathrm{T} \& \mathrm{CM})$ practitioners. Previous research projects have looked at the evaluation of T\&CM interventions; the transition into practice after qualification; and the maintenance of a thriving practice. She is in the final stages of studying for a doctorate in education, looking at the impact of post-qualification education on the professional lives of T\&CM practitioners.

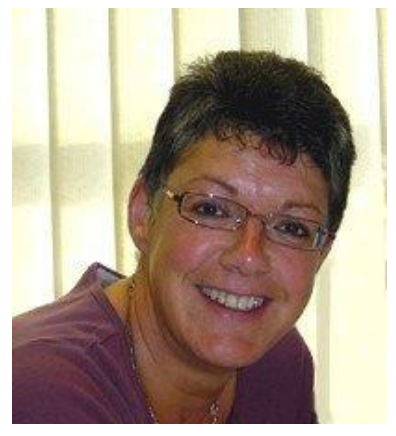

Lynne Barnes is Academic Lead for the BSL \& Deaf Studies team at UCLan. Brought up in the Deaf community, she worked as a teacher of deaf children and as support tutor for post-16 deaf students before setting up the Deaf Studies degree programme in 1993. Lynne also acts as an Adviser to deaf and hard of hearing students across the university. Her research interests are in the pedagogy of deaf learners and access for deaf students within Higher Education. She has organised and contributed papers to numerous conferences, developed a national Access Course for Deaf Students and a bespoke British Sign Language Teacher Training Course and is a consultant on many national and European working groups and projects. Lynne was awarded a National Teaching Fellowship in 2008 for her work in Deaf Studies and in establishing support services for deaf students in H.E. 


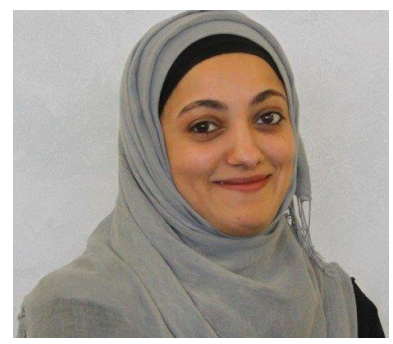

Ridwanah Gurjee - known as Riz - takes responsibility for coordinating the volunteering programme for the University of Central Lancashire (UCLan) and has taken a core role in developing the innovative degree programmes at Foundation, BA and MA level. Riz is Module Leader and Course Leader for a series of part-time, full-time and blended learning teaching programmes, providing people in the community and students from all over the university with specialist experience and training from Volunteering and Community Action, Mentoring in the Community, Practice-Based Research and supporting students in leading independent community research projects. Riz also leads the UCLan quality assurance processes and procedures for all Community Leadership programmes and CPD qualifications with the Institute of Leadership and Management.

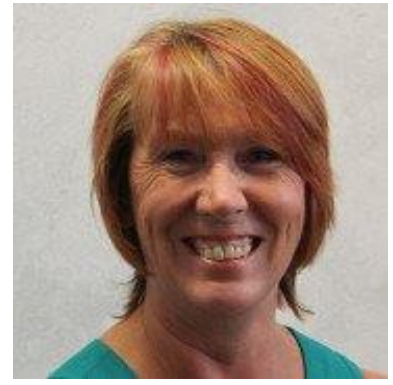

Susan Ramsdale is Senior Lecturer at the University of Central Lancashire. She is a registered mental health nurse and has for the past twelve years worked in the arena of higher education, particularly in relation to mental health. She has worked extensively in the development of pre-registration nursing programmes at both undergraduate and post graduate level but her main focus at present is with the Improving Access to Psychological Therapies (IAPT) initiative for which she is programme lead and represents her university on several national committees. Susan is currently undertaking a Professional Doctorate in Education and is researching the transition from practising nurse to nurse educator which she hopes will inform career pathways for nurses in the future. She is also involved in a large applied research project in the North west of England aimed at improving access to psychological therapies for people post stroke.

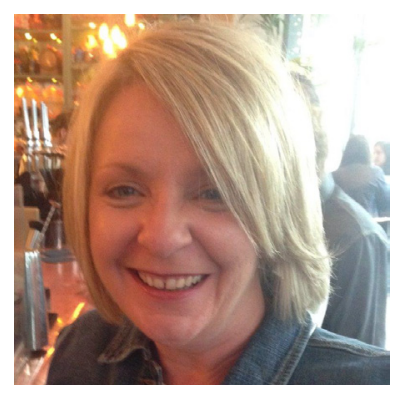

Jacqueline Dodding has taught at The University Centre Blackburn College for the last 5 years on the FdSc Complementary Therapies, BSc (Hons) Professional Practice in Complementary Therapies and BA (Hons) Education Studies. She principally teaches Social Science Research Methods at Levels 4, 5, 6 and supervises undergraduate dissertations. Currently she is in the final year of her Professional Doctorate in Education at The University of Central Lancashire, for which she has undertaken research investigating the experience of Higher Education in Widening Participation students.

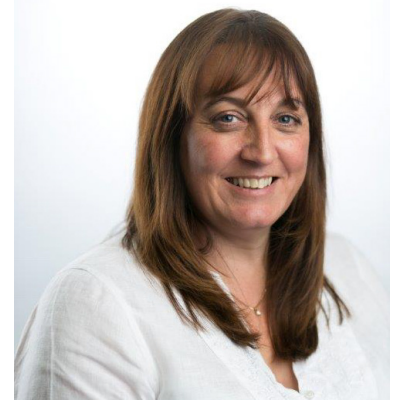

Kathryn Drury is Head of Postgraduate Professional Education in the Faculty of Health and Social Care, at Edge Hill University. As a health professional and educationalist Kathryn works within the senior management team to lead and manage a team of staff within Postgraduate Professional Education. Her duties include management and leadership of staff, chairing postgraduate programmes and exam boards, overall responsibility for the delivery and co-ordination postgraduate programmes and budget responsibilities. Kathryn acts as Programme Lead for the MSc Advanced Fertility Practice, a programme developed with Liverpool Women's NHS Foundation Trust. Kathryn's academic, professional and research interests focus on bridging professional practice and higher education. She is a qualitative educational researcher focussing on health care practice and workforce development. 